\title{
Roland Barthes y el Análisis del Discurso
}

\author{
Luis EnRique Alonso y Carlos Jesús Fernández Rodríguez \\ Universidad Autónoma de Madrid \\ luis.alonso@uam.es \\ carlos.fernandez@uam.es
}

Recibido: 15.03 .2006

Aceptado: 20.11 .2006

\begin{abstract}
«Barthes ha sido siempre antimoderno como todos los verdaderamente modernos»
\end{abstract}

Antoine Compagnon (2005: 404)

«Roland Barthes sólo confería sustancia real al estilo, inflexión que cada vida animada es capaz de imprimir en el río de las palabras donde, como fuego fatuo, aparece y desaparece el ser»

Mario Vargas Llosa (2002: 254)

«Nada más esencial para una sociedad que la clasificación de sus lenguajes. Cambiar esa clasificación, desplazar la palabra, es hacer una revolución»

Roland Barthes (1972: 47)

«El formalismo de Barthes en lo que tiene de más decisivo, su dictamen de que el crítico tiene la misión de reconstruir no el mensaje de la obra sino su sistema - su forma, su estructura - tal vez se entiende mejor así, como la evitación liberadora de lo obvio, como un inmenso gesto de buen gusto».

Susan Sontag (1983: 338)

\section{INTRODUCCIÓN}

En las sociedades contemporáneas, los discursos son uno de los objetos esenciales de investigación por parte de los sociólogos. Según algunos autores, la labor de un analista de discurso debe ser la de describir las regularidades de las realizaciones lingüísticas empleadas para comunicar significados e intenciones (Brown y Yule, 1993: 47). Pero además de describir, el investigador debe comprender e interpretar el discurso. Los discursos - como líneas de enunciación simbólica realizados desde posiciones sociales- no sólo deben ser comprendidos y descifrados por los receptores: también están destinados a ser valorados y apreciados (signos de riqueza) y creídos y obedecidos (signos de autoridad)

EMPIRIA. Revista de Metodología de Ciencias Sociales. N. ${ }^{\circ}$ 12, julio-diciembre, 2006, pp. 11-35. 
(Bourdieu, 1985). Al conocimiento de la estructura y organización del texto (significantes) se debe añadir la profundización en los significados presentes en el mismo (análisis semántico-simbólico), lo que implica la necesidad de una teoría de la interpretación.

Hay un autor que, aunque identificado con el estructuralismo (y con el postestructuralismo en su última etapa), es capaz de proporcionarnos claves útiles para trascender los límites del texto y alcanzar a la sociedad. Se trata del gran semiólogo francés Roland Barthes. Su planteamiento es un análisis que, en sus versiones más formalizadas, se encuadra en un ámbito más semiológico que sociológico, más lingüístico que próximo a un análisis de contenido. En ocasiones esa formalización es tan excesivamente precisa y detallada' que en ningún caso podría adaptarse a los objetivos de una investigación sociológica. Por otra parte, su método evolucionó notablemente a lo largo del tiempo: no coinciden así ni las técnicas ni el objeto de investigación de sus Mitologías (2000) con las del Sistema de la Moda (2003); tampoco las del Análisis estructural del relato (Barthes, 1974) con las de $S / Z$ (1980) o los Ensayos Críticos (1983). Se pueden diferenciar varias etapas dentro de su obra, desde El grado cero de la escritura (1973) hasta La cámara lúcida (1982), su última obra. El propio Barthes las indica en su singular obra Roland Barthes por Roland Barthes (Barthes, 1978: 158): una primera etapa con influencias de Sartre, Marx y Brecht, caracterizada por un deslumbramiento por el lenguaje y por las mitologías sociales; una segunda época eminentemente semiológica tras su aproximación a Saussure, de carácter más cientifista; y un período final en el que el objeto de sus investigaciones se centra en el texto, su análisis y deconstrucción ${ }^{2}$.

Los trabajos e ideas del autor francés pueden ser útiles para un sociólogo interesado en investigar discursos sociales. Es verdad que Barthes ha sido atacado por los lingüistas por la equivocada utilización que, en ocasiones, ha hecho de conceptos corrientes manejados en linguística (signos, sistemas de signos, metalenguajes). Realmente, sus pretensiones formalistas no se corresponden con un método riguroso, especialmente en su primera etapa de las Mitologías, y ha sido muy criticado por ello (Mounin, 1972: 218-226). Sin embargo, puede ser reconocido como un eficaz semiólogo no formalista que aporta interesantes perspectivas dentro de la psicología social y la sociología. La obra de Barthes, tanto en sus inicios menos formalizados como en desarrollos posteriores, va a proporcionar intuiciones válidas para una posible metodología de análisis del discurso.

El estructuralismo, uno de los movimientos intelectuales más fecundos del siglo XX, se consolidó tras la Segunda Guerra Mundial debido, en gran parte, a la obra del antropólogo Claude Lévi-Strauss y un conjunto de jóvenes teóricos de

1 Un ejemplo sería el método expuesto en obras como El sistema de la moda (2003) o S/Z (1980), en los que trabaja con unidades como el sintagma, el vestidema o la lexia.

2 Sobre la evolución del pensamiento de Barthes, se recomienda acudir a Mabel Marro (1999) en su capítulo dedicado a Barthes, o a la magnífica biografía de Louis-Jean Calvet (1992). 
la literatura ${ }^{3}$. La inspiración de esta corriente es la lingüística, considerada por Lévi-Strauss (1968) como el modelo de las ciencias humanas. Todo sistema cultural es un sistema de signos: así, los métodos de la lingüística estructural pueden ser aplicados, por homología, a otros ámbitos de la cultura, entre ellos el análisis del relato. Barthes (1990), que durante una época fue uno de aquellos jovenes teóricos, sigue en cierto modo a Lévi-Strauss cuando establece homologías entre estructuras psicológicas y formaciones sociales, con el lenguaje como mediador universal. Este análisis se aplicó a los campos más diversos (antropología, filosofía, psicoanálisis o incluso el propio marxismo ${ }^{4}$ ), fundamentalmente por un impulso pansemiológico que concebía lo social en un nivel exclusivamente simbólico, dejando de lado procesos tan reales como el del trabajo.

Lévi-Strauss (1980: xi) considerará incluso que la antropología deberá ocupar, «de buena fe, ese campo de la semiología que la lingüística no ha reivindicado todavía para sí [...] Y es que Saussure plantea la semiología como un proyecto pero no llega a desarrollar la evolución que debe seguir esta nueva disciplina en un futuro». Ya que, según el propio Lévi-Strauss, la semiología anunciada por Ferdinand de Saussure desbordaba ya de hecho el campo de los lenguajes hablados, y debía también incluir aquellos signos que no son palabras o sus simples sustitutos; tipo de signos que, aunque a menudo se pase por ellos tan sólo para nombrarlos, nos llevan a significantes de otro orden. Sin embargo, Saussure no profundizó ni se extendió, lamentablemente, en este asunto de gran interés. Por ello, la definición de estructura (elemento central en el paradigma estructuralista) es complicada, dado que su polisemia lleva a múltiples interpretaciones en los también raros escritos de Saussure, siendo finalmente tomada, en su acepción más general, como un conjunto en el que las partes se modifican en virtud de su pertenencia al todo, o como un objeto complejo cuyas partes son solidarias entre sí. En todo caso, el concepto operativo de estructura que utiliza toda esta línea paradigmática: puede ser definida, citando a Umberto Eco, como un modelo construido en virtud de operaciones simplificadoras que permitan uniformar fenómenos diversos bajo un único punto de vista (Eco, 1988: 68). Así, el análisis estructural, del que Barthes ha sido uno de sus más representativos estandartes, no hace otra cosa que abordar diversos objetos de estudio que tienen la

${ }^{3}$ La filosofía estructuralista ha sido considerada como un recambio del existencialismo que dominó la filosofía europea hasta finales de los años cincuenta: frente al pesimismo de éste, el optimismo tecnológico de los años sesenta requiere una visión del mundo diferente (Bolívar, 2001). El estructuralismo, como el funcionalismo en la sociología, se ajusta mejor al capitalismo corporativo propio de la época, en la que primaba una idea de la gran organización, la estructura y los sistemas. Los principales representantes del estructuralismo son el antropólogo Claude Lèvi-Strauss, el psicoanalista Jacques Lacan, los filosofos Louis Althusser y Michel Foucault y, dentro de la semiología y análisis literarios, autores como A. J. Greimas, Roland Barthes, Tzvetan Todorov, Claude Bremond, Gerard Genette o Julia Kristeva. Con carácter de resumen, véase el monumental trabajo de Dosse (2004).

${ }^{4}$ En cuanto a los trabajos dedicados al estudio de la corriente de pensamiento estructuralista, se recomiendan, por su concisión, trabajos como los de Manfred Bierwisch (1982), Antonio Bolívar Botía (2001) o Ibáñez Langlois (1983). 
capacidad de significar; se buscan para ello sus formas subyacentes más simplificadas, que se convierten en condicionantes estructurales. Así, lo que el propio Ferdinand de Saussure inició para la lingüística, convirtiéndola de hecho en una lingüística estructural, Barthes lo convertirá en una semiología general donde todos los procesos sociales comunican y transmiten sentido, sin ser, necesariamente, lenguajes formales con reglas gramaticales estabilizadas ${ }^{5}$.

Ya en los años cincuenta la escuela estructuralista, como referencia académica, había empezado a tener una enorme resonancia en las ciencias humanas y sociales francesas; pero se convierte en un gran movimiento (por no hablar de una gran moda), aplicado a una enorme variedad de temas, en los años sesenta y setenta, en los que alcanza éxito y hegemonía mundial. Como señala el filólogo español José María Pozuelo Yvancos, «el estructuralismo fue un proyecto intelectual de amplio alcance, radicalmente antipositivista, que pretendía descubrir en las distintas facetas del comportamiento (los diferentes textos) principios universales, un código explicativo, una gramática proyectiva común y superior a ellos, que, de modo implícito o subyacente, regía su construcción, su forma. El significado de un elemento es el lugar que ocupa en sus relaciones opositivas con los otros elementos dentro del sistema del que forma parte» (Pozuelo Yvancos, 1994: 79). Este es el punto de partida que había asentado el propio Saussure, al establecer una noción de la lengua como un sistema definido por sus oposiciones internas que generan el sentido, la convierte en la institución social total. De ahí que, en el estructuralismo, todo fenómeno social acaba por reducirse a signo: el mundo se condensa en el texto. El análisis estructural, sea de un cuento, una novela o un mito etnográfico, trata de reducir la información textual a unos ejes de oposición, a sus códigos significantes. El investigador, entonces, se ocupará de decodificar los diferentes hechos discursivos y ordenarlos dentro de una lógica. El modelo, el genotexto, obligará al fenotexto, la expresión (Kristeva, 1978).

Roland Barthes, como hemos señalado, es uno de los representantes más notables de la semiología en Francia. Desde sus primeras obras, tuvo una preocupación fundamental: la relación entre lengua y sociedad. En su obra, como se indicó antes, no se puede hablar de la utilización de una metodología fija de investigación. Su época «cientifista» puede proporcionar más recursos, en cuanto facilita unas herramientas formales para el análisis de textos, especialmente su Introducción al análisis estructural del relato (1974). No obstante, sus Mitologías, como hemos comentado antes, aportan quizá claves semiológicas de mayor interés para el sociólogo. A lo largo de las siguientes páginas haremos un recorrido por dichas claves, realizando una valoración sobre los elementos de interés que la obra de Barthes puede tener para un sociólogo interesado en analizar los discursos sociales, además de mostrar sus limitaciones.

5 Trabajos realizados desde diferentes enfoques que evalúan la contribución de Barthes a la metodología estructural y a la formación de una semiología general son los de Calvet (1992), Culler (1987), Evrard y Tenet (1994) y Milner (2004).

EMPIRIA. Revista de Metodología de Ciencias Sociales. N. ${ }^{\circ}$ 12, julio-diciembre, 2006, pp. 11-35. 


\section{EL ANÁLISIS ESTRUCTURAL DE BARTHES: OBJETIVO, ELEMENTOS, NIVELES.}

Ya en un artículo titulado Sociología y socio-lógica. A propósito de dos obras recientes de Claude Lévi-Strauss, Barthes señala que la «...la sociología es el análisis de las sociedades "escribientes"» (Barthes, 1990: 231); «...la escritura engendra escrituras o, si se prefiere, "literaturas" y a través de estas escrituras o literaturas la sociedad de masas fracciona su realidad en instituciones, prácticas, objetos y hasta en acontecimientos, porque el acontecimiento es ahora siempre escrito" (Ibíd., 232). Para Barthes, la sociedad de masas estructura lo real a través del lenguaje (lo produce y lo escribe). Hace así hincapié en la importancia de los textos en lo social, les otorga un interés en este campo, pero al mismo tiempo los reduce a lo lingüístico: está interesado en el análisis semiológico, en la aplicación del método estructural a todos los fenómenos sociales, reduciéndolos a un sistema de signos. Todo se termina por reducir a un texto, a una dimensión lingüística y simbólica, que se someterá a un análisis estructural: «...el análisis sociológico tiene que ser estructural, no porque los objetos sean estructurados "en sî", sino porque las sociedades no cesan de estructurarlos: la taxonomía sería, en conclusión, el modelo heurístico de una sociología de las superestructuras» (Barthes, 1990: 233). Se responde así a un interés por taxonomizar los lenguajes que atraviesan la sociedad, el mundo; es decir, clasificar los lenguajes e identificar el sentido, pues «nada es más esencial para la sociedad que la clasificación de sus lenguajes. Cambiar esta clasificación, desplazar la palabra, es hacer una revolución» (Barthes, 1972: 47). El lenguaje debe ser esencial para la sociología. Como semiólogo, su preocupación fundamental es, sin duda, el signo (y los códigos).

El análisis estructural permite identificar los signos y códigos dentro del texto que, debajo de lo natural, ocultan lo social. Los sistemas semiológicos construyen lo social, a través de los relatos, los textos, los discursos. No hay signos naturales: todos son culturales aunque las instituciones pretendan naturalizar los signos a través del lenguaje (Marro, 1999: 80). En Mitologías, obra de su primera etapa, ya declaraba que «...sufría al ver confundidos constantemente naturaleza e historia en el relato de nuestra actualidad y quería poner de manifiesto el abuso ideológico que, en mi sentir, se encuentra oculto en la exposición decorativa de lo evidente-por-sí-mismo" (Barthes, 2000: 8). Barthes cree que puede identificar lo ideológico en la sociedad, descubrir el sentido verdadero de los discursos. Proporciona la herramienta analítica para diseccionar ese discurso escrito, ese relato; aporta conceptos como la taxonomía, el sentido, o la clasificación. Como otros autores estructuralistas, persigue esencialmente descubrir los principios de organización subyacentes en el discurso, y las relaciones que estructuran los diferentes elementos de los textos. Existen innumerables formas de relato, y se propone indagar en un posible principio de clasificación del mismo, basado en su estructura, la cual es la forma invariante que da coherencia y consistencia lógica al relato. Su modelo teórico se basa en la linguística. Se centra en 
los códigos, que pueden definirse como campos asociativos, que conforman una organización supratextual de señalizaciones. Establece una homología entre la oración y el discurso, transfiriendo las propiedades semióticas de un nivel al otro. La reducción al código permite examinar los principales núcleos temáticos y funcionales en los textos analizados, y proceder a continuación a comprobar cómo están estructurados. Es un análisis internalista, que tiene por objetivo el descubrimiento de la matriz generadora de todos los relatos del género. La estructura del texto permite conocer la lógica de su sentido, pero esa lógica es en buena parte sociológica: la organización del discurso está influida por factores ideológicos, sociales.

El más acabado ejemplo de esta semiología general es el estudio sobre $E l$ sistema de la moda (2003). Barthes allí realiza un concienzudo y frío análisis de los dictámenes de la moda difundidos por las revistas femeninas y, a partir de este primer análisis, concluye una teoría general de la moda como sistema de representaciones. Juego de elementos, formas y unidades básicas de sentido infinitamente combinables y que, dando la impresión subjetiva de individualidad y soberanía, en realidad cumple la función inconsciente de clasificación y jerarquización social; el código habla a los individuos por medio de los ropajes, que más que ser utilizados por los individuos, son ellos los que utilizan a los individuos para representar un sistema de similitudes y diferencias que reproducen el lenguaje de las apariencias más allá de la historia. El juego del cambio constante, de la actualidad permanente oculta la tendencia a la inmovilidad básica de lo social, a la cristalización de la forma del poder. Esta lógica de la diferenciación es la que ayuda a entender que hoy no hay consumo porque se dé una necesidad objetiva y naturalista de consumir. Lo que hay es producción social de un material de diferencias, de un código de significaciones y de valores de status, sobre el cual se sitúan los bienes, los objetos y las prácticas de consumo. Los bienes se convierten signos distintivos - que pueden ser unos signos de distinción, pero también de vulgaridad desde el momento en que son percibidos relacionalmente- para mostrar que la representación que individuos y grupos ponen inevitablemente de manifiesto, mediante sus prácticas y sus propiedades, forma parte integrante de la realidad social (Barthes, 2003: 245-257). Es la capacidad comunicadora que tienen los bienes la que ayuda a realizar esta diferenciación social ${ }^{6}$.

La actividad por tanto del semiólogo comporta así dos operaciones típicas: recorte y ensamblaje (Barthes, 1983: 258). Se trata por tanto de realizar, como analista, varias tareas: una, localizar y señalar las unidades significativas principales, que son las que articulan el significado del texto, a través de una macrosegmentación del mismo. Ello requiere realizar un «corte sincrónico», donde se lee «lo que es» dentro del texto. Evidentemente, este corte presenta algunas problemáticas: básicamente el ignorar un fluir histórico que puede ha-

- Aspectos fundamentales de la forma de trabajo de Barthes están tratados, con especial claridad, en Trifonas (2004) y Cobast (2002).

EMPIRIA. Revista de Metodología de Ciencias Sociales. N. ${ }^{\circ}$ 12, julio-diciembre, 2006, pp. 11-35. ISSN: 1139-5737 
cerse presente, dejándolo de lado. No obstante, esta pretensión permite una simplificación que va a permitir la comparación entre épocas o etapas, con lo que la historia al final se hace, de alguna forma, presente. Este método permite la comparación entre textos, lo que posibilita constatar la posible evolución de las temáticas a lo largo de diferentes épocas históricas. Se descronologiza el relato, dividiéndose en bloques de significación del mismo modo que, en la lingüística, se divide la oración en sujeto, predicado o en sintagmas. Se elimina el flujo del tiempo, y a través de una comparación entre dos cortes sincrónicos, se puede observar una evolución entre estados. El relato, dividido en enunciados, se combina dando lugar a diferentes sentidos narrativos. El analista del discurso Siegfried Jäger (2003: 88) indica que un corte «sincrónico», en la medida en que se haya convertido en «lo que es», será al mismo tiempo diacrónico e histórico. El sentido se generaría esencialmente por los haces de relaciones dentro de la estructura, en este caso de las existentes entre los elementos del texto; el sentido no nace por repetición sino por diferencia, en un sistema de exclusiones y relaciones (Barthes, 1972: 68-69).

El objetivo del análisis estructural es el definir las reglas (o, más bien, las regularidades) de combinatoria funcional del relato. Para Barthes, «...leer un discurso es, en efecto (...), organizarlo en briznas de estructuras, es esforzarse para llegar a nombres que "resumen" más o menos la profusa sucesión de las señalizaciones, es proceder en uno mismo, en el momento mismo en que uno "devora» la historia, a realizar ajustes nominales, es domesticar incesantemente lo que uno lee, apelando para ello a nombres conocidos, surgidos del vasto código anterior de la lectura...» (Barthes, 1990: 208). De un texto ideal «en bruto» nace la infinidad de las narraciones, cuyo sentido es captado ordenando las lógicas que los atraviesan. Se busca reducir cada texto a los vectores o ejes que lo organizan. Para identificar el sentido, se reduce el texto a un esquema lógico de relaciones entre elementos. El análisis estructural permite considerar la obra no como un mero documento histórico, sino como una unidad significativa autónoma, separada de otros discursos y del flujo del tiempo. Esta concepción de la obra, esto es, del texto, se basa, según Barthes, en los siguientes principios:

a) Principio de formalización. Es, esencialmente, un principio de abstracción. «El análisis estructural del relato es fundamentalmente comparativo: busca formas y no un contenido. [...] Un análisis del relato tiene exactamente la misma tarea: tiene que reunir relatos, un corpus de relatos, para intentar extraer una estructura» (Barthes, 1990: 288). Sobre un corpus de obras el análisis permanece en el nivel de las relaciones, no en el de los significados. Es la búsqueda de la sintaxis.

b) Principio de permanencia. Son las diferencias de sentido: «...se intentan encontrar las diferencias de forma que vienen atestiguadas mediante diferencias de contenido; estas diferencias son rasgos pertinentes y no pertinentes» (Ibíd., 288-289). Las diferencias entre las combinaciones sígnicas marcarán el sentido del enunciado. 
c) Principio de pluralidad. Indaga el lugar posible de los sentidos (pluralidad de sentidos). Analiza los códigos, pero no los interpreta. Distingue entre los códigos de acción o de comportamiento, códigos del descubrimiento de la verdad (hermenéutica), códigos semióticos (características o descripciones), códigos culturales (citas) y códigos simbólicos (arquitectura simbólica del lenguaje).

d) Disposiciones operativas. Son las tres operaciones que deben realizarse: segmentación del texto (cuadriculación); inventario de los códigos; y coordinación (establecimiento de correlaciones con otros textos o intertextualidad). En el manejo de la intertextualidad se puede vislumbrar un posible acceso a la dimensión pragmática del discurso.

Barthes ofrece en estos principios una visión quizá excesivamente detallada y formalizada del trabajo a realizar sobre el texto. Pero a partir de aquí, el autor nos propone un análisis de la organización textual que arroja algunas claves de gran interés.

\section{LA ORGANIZACIÓN DEL TEXTO. CATEGORIZACIÓN Y CLASIFICACIÓN}

La organización del texto se describe en la obra de Barthes desde una clave puramente estructuralista. La cobertura funcional del relato impone una organización de relevos (relais), cuya unidad de base es la secuencia (nudos unidos solidariamente). La secuencia es siempre nombrable: problema, idea, lucha, éxito, siendo los actos meras alternativas. «La secuencia es, pues, si se quiere, una unidad lógica amenazada: esto es lo que la justifica como mínimo. Pero también está fundada por lo máximo: cerrada sobre sus funciones, oculta bajo un nombre, la secuencia misma constituye una unidad nueva, presta para funcionar como simple término de otra secuencia más prolongada» (Barthes, 1990: 183). La secuencia se puede definir como una concatenación de acciones. Pueden ser de apertura y cierre, de argumentación, narrativa y de reparación. La tarea, por tanto, consiste conseguir una descripción estructural de la ilusión cronológica; «...la lógica narrativa es quien debe dar cuenta del tiempo narrativo» (Ibíd., 180). Como se señaló con anterioridad, este es el elemento fundamental del análisis estructural: la ahistoricidad, la eliminación de lo histórico para transformar el texto en un sistema 16gico de relaciones. Esa lógica será la que otorgue el sentido al relato ${ }^{7}$. El análisis

${ }^{7}$ Otros conceptos de interés son los de isotopía y macrorreglas. Para Greimas (1973), el sentido del discurso viene marcado por las isotopías, que pueden describirse asimismo como oposiciones que se pueden localizar dentro del texto, y que pueden ser de muchos tipos: alternativas, polares, seriales, combinadas, etc. Otra noción interesante es la de las macroestructuras de Teun A. van Dijk, que definen las estructuras de comprensión y la forma global del consenso ideológico básico. La macroestructura cuenta con unas macrorreglas que organizan el texto (supresión-selección; generalización; y construcción-integración) (van Dijk, 1997). 
estructural barthesiano distingue en la Introducción al análisis estructural del relato tres niveles diferentes de operaciones: el nivel de las funciones, el nivel de las acciones y el nivel de la narración o del discurso, ligadas entre sí en una integración progresiva.

El primer nivel es el de las Funciones. Todo sistema semiológico es una combinación de unidades. También lo es el texto. Barthes distingue, dentro del texto, entre dos elementos principales: los núcleos o funciones bisagra, y las catálisis (funciones de naturaleza completiva). «Nudos y catálisis, indicios e informantes (...), tales son, pareciera, las primeras clases en que se pueden distribuir las unidades del nivel funcional. [...]. Las catálisis, los indicios y los informantes tienen en efecto un carácter común: son expansiones, si se las compara con núcleos: los núcleos (...) constituyen conjuntos finitos de términos poco numerosos, están regidos por una lógica, son a la vez necesarios y suficientes: una vez dado este armazón, las otras unidades vienen a rellenarla según un modo de proliferación en principio infinito...» (Barthes, 1974: 22). Son segmentos de acción. Barthes denomina funciones cardinales o núcleos a las funciones importantes que constituyen el eje de la narración, afectando directamente al desarrollo de la narración; las que simplemente se limitan a rellenar el resto del espacio narrativo las llama catálisis, que aunque tienen carácter funcional, dependen de los núcleos (son expresión de detalles o de acciones poco importantes). Para poder realizar esta distinción entre núcleo y catálisis, existen diversas aproximaciones. Indica así que «dado que todo sistema es la combinación de unidades cuyas clases son conocidas, hay que dividir primero el relato y determinar los segmentos del discurso narrativo que se puedan distribuir en un pequeño número de clases, en una palabra, hay que definir las unidades narrativas mínimas» (lbíd., 16). Esto implica centrarse en primer lugar en la búsqueda (localización) de los llamados «núcleos de sentido» que componen la comunicación, dando especial relevancia a su presencia o frecuencia de aparición (Clemente y Santalla, 1991: 40). Existen varias definiciones de función. Para Barthes, «la función es evidentemente, desde el punto de vista linguístico, una unidad de contenido: es "lo que quiere decir" un enunciado lo que lo constituye en unidad formal y no la forma en la que está dicho» (Barthes, 1974: 17). Propp ya estableció en su Morfología del cuento ruso la utilización de las funciones dentro del relato: «Por función, entendemos la acción de un personaje definida desde el punto de vista de su significación en el desarrollo de la intriga» (Propp, 1981: 33). Sobre las funciones se van construyendo las diferentes secuencias. Las secuencias principales son las de apertura y cierre, secuencias de argumentación, secuencias narrativas, y secuencias de reparación. Así, se procede a una descronologización para poder así reconstruir una lógica de la acción ${ }^{8}$. Por otro lado, la

${ }^{8}$ Como señala Ricoeur (1973: 40): «De esta manera se construye una lógica de la acción a modo de encadenamiento de los "núcleos de acción" constitutivos de la continuidad estructural. Así resulta posible descronologizar el relato y establecer, por debajo del tiempo narrativo, una lógica narrativa. En última instancia, el relato resulta ser una combinación de ciertas unidades dramáticas - prome-

EMPIRIA. Revista de Metodología de Ciencias Sociales. N.o 12, julio-diciembre, 2006, pp. 11-35. ISSN: 1139-5737 
narración contiene índices que informan al lector acerca de las circunstancia del relato, y que pretenden ser de dos tipos: índices propiamente dichos, que describen la personalidad de un agente de la narración, ambiente o principio filosófico, o informantes, que identifican el espacio y el tiempo en el que se desarrolla la acción (Pavel, 1999: 118-119; también Barthes, 1990). La función puede considerarse como unidad de contenido o unidad temática, siendo la principal unidad de trabajo?.

El segundo nivel es el de las acciones, que es el que incluye a los personajes. En cada uno de los textos se encuentran unos sujetos concretos, marcados por unos atributos característicos. No son sujetos reales, sino personajes marcados por su función en el relato: el actor es así otro nivel más, susceptible de ser analizado desde la semiología. Es preciso inventariar en cada uno de los textos los personajes, los actantes, que participan de la acción. Una vez identificados, se prestará atención a su papel actancial, sus características y las relaciones existentes entre ellos, es decir, como están situados en la red estructural. En general, la tendencia de los formalistas consistirá en clasificar los papeles de los actores en algunos papeles básicos, $y$, de ser posible, por parejas de oposiciones: donante - destinatario, el que promete- el que recibe la promesa, etc. Se crea así una jerarquía de actuantes, paralela a la jerarquía de las acciones, y de la misma manera que existen niveles en las secuencias, hay también niveles de personajes (Ricoeur, 1973: 41). Cada uno de estos deberá ser definido a través de un conjunto de cualidades que se infieren del texto y que permiten situar su posición estructural.

El tercer nivel es el de la narración, y es el que incluye los signos del relato. En este nivel, el relato es considerado como un todo. Se trata de describir el esquema narrativo del relato, su estructura lógica. «El nivel narracional está, pues, ocupado por los signos de la narratividad, el conjunto de los operadores que reintegran funciones y acciones a la comunidad narrativa, articulada sobre su donante y su destinatario» (Barthes, 1990: 193); «...más allá del nivel narracional, comienza el mundo, es decir los otros sistemas (sociales, económicos, ideológicos)...» (lbíd., 194). Entre estos signos de la narración o código narrativo, deben destacarse especialmente dos: el estatuto del narrador, que puede tener un tono personal o apersonal, y la relación del relato con el mundo que lo rodea. Otro aspecto fundamental en el análisis narracional es el análisis del lugar (topos, locus). Para Barthes, «...los loci forman, pues, esa reserva muy particular que constituye el alfabeto: un cuerpo de formas privadas de sentido en sí mismas, pero que concurren al sentido mediante selección, combinación, actualización» (Ibíd., 135). Se incluyen aquí los llamados lugares comunes, los llamados tópicos o To-

ter, traicionar, impedir, ayudar, etc.- que constituyen los paradigmas de la acción. Una secuencia es entonces una serie de dichos núcleos de acción donde cada uno de ellos cierra una alternativa abierta por el precedente; los puntos de orientación del relato marcan los momentos de "riesgo" que hacen de cada secuencia una unidad lógica "amenazada"".

9 Otra distinción de interés es la de funciones distribucionales (que llevan a relatos funcionales) y funciones integrativas (que llevan a relatos indiciales).

EMPIRIA. Revista de Metodología de Ciencias Sociales. N. ${ }^{\circ}$ 12, julio-diciembre, 2006, pp. 11-35.

ISSN: 1139-5737 
poi, que son un conjunto de símbolos colectivos y estereotipos culturales que se pueden reflejar en el texto ${ }^{10}$. Este cúmulo de símbolos colectivos proporciona un repertorio de imágenes representativas de la realidad societal (Jäger, 2003: 65), a través de las cuales se interpreta la producción de realidad que realiza el discurso. Para el semiólogo, «la sociedad de masas tiende siempre a estereotiparse en torno a sentidos definidos, nombrados, separados» (Barthes, 2003: 431). Aquí hay un posible acceso a una pragmática, una relación del texto con el contexto.

Tras establecer (después de trabajar sobre los distintos niveles narrativos) los elementos, el siguiente paso es proceder a reconstruir su lógica combinatoria. Para ello, el proceso debe permitir una categorización de las distintas unidades significativas en una red de relaciones, proporcionando modelos susceptibles de clasificación. Así, «la categorización es una operación de clasificación de elementos constitutivos de un conjunto por diferenciación, tras la agrupación por género (analogía), a través de criterios previamente definidos» (Bardin, 1986: 90). Se debe crear un sistema útil de categorías, en dos etapas: la primera, el inventario, que se consigue al aislar los elementos. La segunda, la clasificación, distribuyendo los elementos e imponiendo una cierta organización. Las categorías deben crearse por un método de tanteo (trial and error method), y sus fuentes serán la teoría y los objetivos de la investigación. Quizá sea excesivo plantearse el hallar la matriz significante a la que alude Barthes en alguna de sus obras (2003), esto es, una matriz que permita la transformación del texto a través de la permutación de elementos. Pero sí se puede indagar en la búsqueda de un Armazón Básico del texto, sobre el que surgirán evidentemente variantes ${ }^{11}$.

Hasta el momento, el análisis se ha centrado exclusivamente en la organización del relato y las combinaciones entre sus elementos (relaciones): esto es, en las propiedades internas del discurso. Descronologizado el discurso, se ha dividido, ordenado y clasificado en esquemas. Se ha descifrado su lógica pero, como dice Voloshinov, «la modalidad temático-analítica sólo puede tener un desarrollo más o menos extenso y sustantivo en un contexto autorial algo racionalista y dogmático...» (Voloshinov, 1992: 173). Sería necesario trascender esta visión monológica, poniendo el discurso en relación con el contexto social en el que se despliega. Los enunciados, hasta ahora estudiados como significantes, tienen también significado, el cual está marcado por lo social. El plano lógico-formal debe ser completado, así, con uno de carácter semántico-pragmático.

${ }^{10}$ Para van Dijk, los topoi son lugares comunes que actúan como parte de la argumentación básica: «una de las implicaciones discursivas del uso del topoi es que, como argumentos estándar, no es necesario defenderlos: son criterios básicos de la argumentación» (van Dijk, 2003: 68).

${ }^{11}$ Se pueden aprovechar aportaciones téricas de otros autores como Todorov, que distingue dentro del análisis estructural del relato los siguientes aspectos: Lógica de las acciones, relaciones entre personajes, reglas de acción, el tiempo del relato, aspectos del relato tales como la posición del narrador y la evolución de dicha posición a lo largo del texto, modos del relato, infracciones al orden secuencial del relato, etc. (Todorov, 1974). 


\section{EL PLANO MITOLOGICO O EL ACCESO A UNA SEMÁNTICA DEL DISCURSO}

Cada individuo, en principio, parece afrontar individualmente su relación con los signos, a través de interacciones discursivas. Sin embargo, las interpretaciones que esos individuos hacen de los signos no van a ser individuales, sino que estarán mediadas por la realidad social. La comunicación entre los diferentes miembros de una comunidad se realiza a través de sistemas de signos, de los cuales el lenguaje es el más importante. Éste es una «cosa social», es el principal instrumento de comunicación y fundamental por su condición de simbolizador universal (Beltrán, 1991a: 137). Creado socialmente, el lenguaje se impone al individuo: no sólo filtra su percepción, también produce su pensamiento y construye su conocimiento del mundo (Ibíd., 143). El significado de las palabras es atribuido a partir de las interpretaciones dominantes en la sociedad. Los fenómenos discursivos son sociales: cuando la gente habla, escucha, escribe o lee, lo hacen de una manera que está determinada por la sociedad y que tiene efectos sobre la misma (Fairclough, 1990: 23). Pero no siempre todos los símbolos significan lo mismo. Existen en todas las sociedades una heterogeneidad en el uso de la lengua, que varía no sólo por cuestiones especiales o temporales; también varía en función del contexto (estilísticamente) o por diferencias sociales (hablas estratificadas). Es un lenguaje vivo. Por tanto, el discurso se abre a distintas interpretaciones, marcadas por la posición en la que se encuentren los actores sociales en la estructura social. La labor del investigador del discurso debe ser la de decodificar estos símbolos sobre los que no se ha alcanzado un consenso total. Al leer un texto, se localizan determinados símbolos que aluden a un aspecto de la realidad social. Esos símbolos pueden estar organizados en forma de diversas figuras. Una de ellas es la Mitología, una de las grandes aportaciones de Barthes.

Un mito es una representación colectiva en la que se reflejan determinadas prácticas y funciones sociales, y que se plasma en una narración. Estos relatos suelen tener un fundamento histórico-real, $y$ recogen un acto fundacional de la sociedad o la aparición de una regla o una costumbre. El mito, al ser narrado, se puede concebir como un sistema semiológico. El antropólogo Pierre Maranda (1999: 225) lo entiende así: «El mito es una narración dramática, oral o escrita, que emerge a partir de los cimientos semióticos de una sociedad. Es, por tanto, la realización implícita de una matriz lista para la construcción de significados, y como tal, se oculta tras una gran variedad de géneros: es una manifestación de la ideología (y por tanto, un medio para acceder a ella), genera toda clase de discursos semióticos en el arte, la política, la literatura, los rituales, los juegos, la ciencia, etc...». La Mitología es un sistema construido a partir de un conjunto de mitos, y se encuentra más allá de la historia.

El enfoque estructural ha prestado atención a esta cuestión desde dos ángulos diferentes. Por un lado, el antropólogo Lévi-Strauss (1982) se ha centrado en las mitologías presentes en las sociedades «primitivas», concibiéndolas como sis- 
temas de significación cerrados (mitemas) que están presentes de una manera u otra en todas las culturas ${ }^{12}$. Son grandes relatos que articulan la sociedad y explican, de una $u$ otra manera, el origen de la misma ${ }^{13}$. Por otro lado, está la aproximación del primer Roland Barthes, que se centra en la mitología de las sociedades actuales. Los mitos no son sólo propios de las sociedades «primitivas», también están presentes en la cultura burguesa, aunque no conforman grandes relatos estructurales sino, más bien, un corpus de discursos (Barthes, 1987: 83-84). Para Barthes, la vida cotidiana se perciben conjuntos de signos y símbolos que, pese a su aparente naturalidad, son realmente ideológicos: a la manera de un reflejo invertido, presentan lo social como natural. A estos signos, estructurados en discursos, los denomina Mitos. Estos operan como estructuras organizativas intersubjetivas de significación, que se organizan, a su vez, en lo que se podría denominar una mitología o ideología (Vázquez y Aldea, 1991: 15). Ejercen su función simbólica mediante el instrumento específico del relato (Ricoeur, 1969: 459). Los hechos sociales se pueden interpretar como un sistema de valores que, sin ser una narración en sentido estricto, también circunscriben un lenguaje que naturaliza, saca de la historia y convierte en mágicas (míticas) las representaciones cotidianas modernas (Alonso, 1998: 161). Un determinado signo puede tener asociados distintos significados sociales, a un mismo significante. Se ha tratado de imponer un consenso sobre el significado, pero ese acuerdo no se ha alcanzado. Se convierte entonces en impuesto, y al ser dictado por la autoridad o el poder dominante parece convertirse en su significado «natural»: es decir, en mito.

La Mitología, así, tiene como función integrar al individuo en un determinado orden simbólico a través de la imposición de unos significados. En un nivel manifiesto, éstos pasarán a formar parte de la ideología dominante. Sin embargo, a nivel latente el signo adquirirá una condición polisémica, al quedar abierto a interpretaciones desde otras posiciones sociales. Barthes explica el mito a partir del signo. Desde el punto de vista formal de la semiología, el signo es un sistema formal compuesto de significante y significado. El mito es un sistema semiológico en el que el signo actúa como significante, agrupando objeto e imagen; más allá del mismo, existiría un significado oculto, latente (Barthes, 2000: 203-206). El mito, como signo que es, también está compuesto de significado y significante, pero respecto a la lengua es un sistema secundario. Lo que era signo en el siste-

12 La mitología tiene para Lévi-Strauss dos características. Es estática, pues «...encontramos los mismos elementos mitológicos combinados de infinitas maneras, pero en un sistema cerrado, por contraposición a la historia, que, evidentemente, es un sistema abierto» (Lévi-Strauss, 1987: 63); en segundo lugar, las mitologías existen en todas las culturas: «... las historias de carácter mitológico son, o lo parecen, arbitrarias, sin significado, absurdas, pero a pesar de todo diríase que reaparece un poco en todas partes» (Lévi-Strauss, 1987: 30). Trata de reducirlos a un tema con variaciones. LéviStrauss, que tiene como objetivo no mostrar cómo piensan los hombres en los mitos, sino cómo los mitos se piensan en los hombres (1982: 21), indagará en los códigos buscando las reglas de traducibilidad recíproca de varios mitos.

${ }_{13}$ Greimas (1973), siguiendo a Lévi-Strauss, se aproxima a los componentes semíticos del mito como gran relato estructural, descomponiéndolos en armadura, mensaje y código.

EMPIRIA. Revista de Metodología de Ciencias Sociales. N. ${ }^{\circ}$ 12, julio-diciembre, 2006, pp. 11-35. ISSN: 1139-5737 
ma primario (el de la lengua) es aquí un significante. El mito representa, así, una deformación ${ }^{14}$ : enmascara al signo, y «cuando más mítica es la función (...), más enmascara al signo...» (Barthes, 2003: 303). La característica esencial del mito es la unión entre la palabra y el sentido ideológico concreto que, por una parte, determina la evolución de las representaciones mitológicas, y, por otra, la percepción específica de formas linguíísticas, significaciones y combinaciones estilísticas. Representa un sistema dual: por una parte, es un sistema denotado, esto es, que como signo hace referencia a un objeto o denotatum que indica o anuncia. Por otro lado, es un sistema connotado, que sugiere un valor secundario, que se relaciona como signo con otro objeto, con otro significado.

También tiene a su cargo fundamentar como naturaleza la historia y como eternidad la contingencia (Barthes, 2000: 237); por ello, presenta lo social como natural, es así un reflejo invertido de la realidad. Si el mito garantiza la permanencia de la totalidad del orden cósmico en torno al orden que la sociedad ya ha realizado de hecho en el interior de sus fronteras (Debord, 2000: 119), entonces es imprescindible descifrar ese mito, proceder a su des-mixtificación ${ }^{15}$ para que pueda ser comprendido. Su estudio tiene como objetivo su desciframiento, y se debe hacer desde una visión interpretativa o hermenéutica. La interpretación tiene como objetivo decodificar el símbolo, traer a la superficie su sentido oculto: ésta debería ser la base del trabajo del analista, el profundizar en la connotación, des-ocultar significados latentes. El sociólogo, por analogía, actuará así como un cazador de mitos (Elias, 1995: 62). Aquí está el principal mérito de la aproximación del Barthes pre-cientifista: va más allá de la narración tratando de descubrir lo latente, lo connotado del mensaje. Hay un componente sociológico en la aproximación a la comunicación, al signo. Ciertos ejemplos de literatura de masas, como los libros de autoayuda o la literatura gerencial, tienen una eficacia de persuasión semejante a reproducciones mitológicas compartidas.

Las lecturas del mito se pueden realizar desde la semiología o desde una aproximación hermenéutica, que aquí se denominará semántica y pragmática. Pero la semiología lo define no por el objeto de su mensaje sino por la forma en que se profiere (Barthes, 2000: 199): es decir, por sus límites formales. Barthes se queda en el nivel de las formas incluso en su época menos formalista. Posteriormente, propondrá directamente sustituir el desciframiento del Mito por el del Signo, la Mitoclastia por una Semioclastia en la que el estudio del mito se deja de lado para acercarse al lenguaje, la fraseología o el idiolecto (Barthes, 1987:

14 Barthes indica que el mito desplaza de nivel el sistema formal de las primeras significaciones, en una relación de deformación con el sentido que admite varias lecturas (Barthes, 2000: 206).

${ }^{15}$ La corriente del Análisis Crítico del Discurso (ACD) asume que uno de sus objetivos consiste en «desmitificar los discursos», mediante un descifrado de las ideologías presentes en los mismos (Wodak y Meyer, 2003). Umberto Eco, al investigar los símbolos de la cultura de masas, cree que se debe realizar el siguiente procedimiento: una investigación sobre los objetivos que encarna la imagen (aquello que está más allá de la imagen); por otro, un proceso de desmistificación consistente en identificar aquello que está en la imagen misma, no solamente las exigencias inconscientes que la han promovido, sino una persuasión oculta motivada por fines económicos determinados (Eco, 1985: 245). 
86): abandona lo social para irse a lo semiótico. Por tanto, para el sociólogo es imprescindible una aproximación semántica adicional, que permita profundizar en el mensaje, trascender el formalismo y permitir el desvelamiento de aquellos elementos que puedan constituirse dentro de una dicotomía de lo sagrado y lo profano (Eliade, 1967), si procediese. La aproximación barthesiana va a dar una base para la interpretación, pero es necesario completarla a través de su conexión con los contextos y una teoría más elaborada de lo simbólico. Las Mitologías son construcciones sociales, y a través de ellas es posible sobrepasar el nivel formal del análisis estructural con una apertura a lo social: no obstante, el sociólogo debe ir más lejos, perseguir una verdadera apertura al discurso.

Esa apertura del discurso a lo social permitiría al analista descubrir en el discurso lo ideológico, situando las ideologías que sustentan dichas mitologías en relación directa con las relaciones sociales que han originado dicho discurso. El actante puede transformarse ahora en sujeto, desempeñando funciones tanto de hablante como de oyente. La ideología latente se hace manifiesta, y se puede analizar la forma de alcanzar los consensos respecto a los significados. El hablante debe ser concebido, a partir de aquí, como un ideólogo; sus palabras, así, se deben considerar ideologemas, puntos de vista especiales acerca del mundo que pretenden una significación social (Bajtin, 1991: 150). Los ideologemas suponen vías de acceso tanto a otros discursos como al contexto socioeconómico e histórico, y permiten que el discurso se entrelace con la sociología en una sociohermenéutica.

\section{LIMITACIONES DEL ANÁLISIS ESTRUCTURAL. UNA CRITICA NO LINGÜÍSTICA A ROLAND BARTHES}

¿Encaja este análisis estructural del relato dentro de una temática sociológica? En general, las relaciones entre sociología y lenguaje han sido complejas: como señala Beltrán (1991a: 137), «lo que a la sociología le interesa en el lenguaje es su palmaria condición de realidad social, no sus aspectos propiamente lingüísticos ni su relevancia para la psicología». No obstante, el análisis estructural puede ser un método útil siempre que se sea consciente de sus limitaciones. En primer lugar, se debe aplicar a un conjunto de relatos que tengan un verdadero interés sociológico y que a la vez permitan que el método se aplique. Según Paul Ricoeur (1973: 89), el análisis estructural puede tener éxito en los casos en que se puedan cumplir varias condiciones: trabajar sobre un corpus constituido, detenido, cerrado; establecer inventarios de elementos y unidades, y colocarlos en relaciones de oposición. En definitiva, poder establecer un álgebra, una combinatoria de esos elementos. El sociólogo debe tener estos aspectos muy en cuenta, y aplicar esta metodología a un objeto de estudio con estas características.

Hay que empezar recordando que es muy criticada la apuesta del Barthes más analítico por un objeto teórico tan estático como el de estructura, al que ge- 
neralmente se le reprocha su presuposición de orden subyacente lo que, de manera implícita, choca con la propia construcción conflictiva de lo social y sus prácticas. Es, por lo tanto un comentario frecuente el que realizan Millet y Varin D'Ainvelle en su ya clásica recapitulación sobre la primera singladura estructuralista: «la noción de estructura lleva con ella el sueño de una nueva unidad al fin comprendida, asegurada y garantizada, recuperar la dirección del objeto que aprisiona en la red de su construcción [...] una construcción sometida a un orden» (1975: 90). Existe, pues, en la primera versión del estructuralismo un afán por el orden, el dominio y el control de la realidad, paradójicamente, no demasiado diferente al del positivismo. Por otro lado, asistimos a una peligrosa hipóstasis del sistema. El lingüista chileno J. M. Ibáñez Langlois achaca ya al propio Saussure que «al despachar el lenguaje como facultad (por demasiado metafísico) y el habla como acto (por singular y concreta), estaba ya convirtiendo su tercer término, la lengua, en una substancia o hipóstasis devoradora que, en la formalidad abstracta de su estructura (en la inmanencia de lo sistémico), debía absorber tanto el significado como el pensamiento y como el propio sujeto humano» (Ibáñez Langlois, 1983: 48). De nuevo aparece la ahistorización y la despersonalización de la lengua. Hay quizá una excesiva pretensión teórica que puede dar lugar al peligro de hacer pasar los diseños teóricos del investigador por la realidad misma, selección de argumentos que puede conducir al lector a confundir el modelo estructural con la sociedad misma o caer en la conocida parábola borgiana en su cuento «El rigor de la ciencia» (Borges, 1990): confundir el mapa con el territorio. Por ello, se corre el peligro de encerrarnos en el mundo ideal de la lógica formal de las relaciones y articulaciones linguísticas, esto es: «el concepto de la lengua como formadora de la llamada realidad, como categorizadora del llamado mundo, es un concepto muy querido de la linguiística estructural, y ese concepto se relaciona con la presunta irrealidad de la realidad extralingüística: la lengua constituye lo real y no al revés» (Ibáñez Langlois 1983: 48). Este es un aspecto determinante en cuanto al lugar que ocupa el sujeto y la historia dentro del esquema interpretativo del estructuralismo en su conjunto.

Un análisis que se asienta sobre esas bases teóricas tiene un número importante de limitaciones, propias de los presupuestos de partida metodológicos de esta corriente. Barthes señala que en el estructuralismo el sistema prevalece sobre el ser de los objetos (Barthes, 1978: 51), y efectivamente, este es el problema: el estructuralismo proporciona una metodología reductora, eficaz para una actividad de taxonomización, pero limitada a la hora de interpretar el texto. $\mathrm{El}$ análisis barthesiano de su Introducción al análisis estructural del relato puede arrojar un pequeño problema, y es el de implicar un trabajo excesivamente detallado, en el que la precisión del análisis semiológico se imponga sobre la relevancia. Por ello, se debe sortear la formalización irrelevante, trascendiendo el nivel del sintagma, y completando el trabajo con una aproximación desde la semántica y la pragmática. Barthes es una referencia válida en el caso de indagar en los aspectos formales (próximos a la semiología), pero por otra parte va a aportar concepciones de gran interés que se acercan a la sociología (lo social), 
como su noción de mitología o el eje de sistema denotado frente a sistema connotado.

La crítica que se ha hecho a estos métodos estructurales (y que es aplicable también a la obra de Barthes, si bien sus trabajos menos formalistas hacen que no se pierda en la clausura de los signos) se ha centrado en el pansemiologismo que reduce toda la realidad social a códigos ${ }^{16}$, ejerciendo un efecto ideológico ${ }^{17}$. Este exceso no quiere decir que muchas de las realidades estudiadas por los sociólogos admitan una lectura en la que sean signo de otra cosa: lo simbólico enmascara los hechos de estudio. Sin embargo, de ahí a suponer que toda realidad social sea signo y sólo sea susceptible de análisis semiológico, media una gran distancia (Beltrán, 1991b: 40-41). Otro aspecto criticable es la negación del papel del sujeto en los hechos sociales: éste se encuentra inserto dentro de una red, estructura o máquina simbólica y, como en el sistema de signos, lo fundamental es su relación respecto al sistema. El objeto de las ciencias humanas es el de «disolver el hombre» (Lévi-Strauss, 2002: 357): el sujeto se reduce a un mero actante, a un signo ${ }^{18}$. En la elaboración del texto, incluso se sugiere la muerte del autor (Barthes, 1987: 65-71), que queda reducido a ser un agente limitado a gestionar los códigos lingüísticos que le proporciona la sociedad. Se obvia la dialéctica siempre presente en el devenir social, y la continua negociación del significado entre los actores y grupos. La formalización desplaza al sujeto y también a la historia.

En el estructuralismo, como hace Saussure en su formulación del análisis lingüístico, se da prioridad de los elementos sincrónicos frente a los diacrónicos. Esto no quiere decir que el estructuralismo niegue la historia, simplemente la desplaza fuera del análisis. Lo importante son las relaciones dentro de un sistema, el conjunto de diferencias y oposiciones entre términos y signos: «percibimos diferencias y, gracias a esta percepción, el mundo «toma forma» ante nosotros y para nosotros» (Greimas, 1973: 28). El sistema es un sistema cerrado, donde se clausura el objeto ${ }^{19}$. En el caso del texto, «...las denominaciones contenidas en el texto son determinadas por las definiciones que se hayan presentes

${ }^{16}$ Desde el marxismo situacionista, Debord criticaba que «el estructuralismo es el pensamiento garantizado por el Estado que piensa las actuales condiciones de la "comunicación" como si fueran un absoluto. Su forma de estudiar el código de los mensajes en cuanto tal no es sino el producto y el reconocimiento de una sociedad en la cual la comunicación existe bajo la forma de una cascada de señales jerarquizadas» (Debord, 2000: 164). Desde un marxismo más tradicional, el pensamiento estructuralista recibe también las críticas de Lefevbre (1975).

${ }^{17}$ Bourdieu (1985: 7) señala que la lingüística estructural ejercía un efecto ideológico, separando el instrumento lingǘrstico de las condiciones sociales de producción y utilización del discurso.

18 Para Narciso Pizarro, esta semiología del relato coincide en sus planteamientos con una sociología de carácter funcionalista, en la que la unidad de análisis sería el acto-unidad (unity-act). Este acto-unidad vincularia al actor a las orientaciones (normativas) de la acción que definen los fines y los medios de las mismas, definidos a su vez por los valores (Pizarro, 1979: 85).

${ }_{19}$ Kristeva lo define de forma significativa: «El círculo se cierra: la concepción de la lengua como signo se extiende sobre toda actividad translingüística, la organiza dentro de sus esquemas y según sus reglas, y refleja toda práctica ordenada como una estructura ("una entidad autónoma con dependencias internas") dependiente de la comunicación denotativa verbal» (Kristeva, 1978: 77-78).

EMPIRIA. Revista de Metodología de Ciencias Sociales. N. ${ }^{\circ}$ 12, julio-diciembre, 2006, pp. 11-35. ISSN: $1139-5737$ 
en él y únicamente por ellas, de tal suerte que el texto constituye un microuniverso semántico cerrado sobre sí mismo» (Ibíd., 142). Existe un cierre, una codificación del sentido: la finalidad de la organización es señalar cómo se organiza el mismo. Esto supone que el relato queda aislado de la sociedad y los sujetos. Centrado como está en las relaciones y la estructura, el método de análisis estructural olvida realizar la interpretación de los signos. Como señala Ricoeur, el lenguaje ya no aparece como la mediación entre mentes y cosas. Constituye un mundo en sí mismo, dentro del cual cada elemento sólo se refiere a elementos del mismo sistema, gracias a la interacción de oposiciones y diferencias constitutivas del sistema. En pocas palabras, el lenguaje ya no es tratado como «una forma de vida», como diría Wittgenstein, sino como un sistema autosuficiente de relaciones internas. En este punto extremo, el lenguaje como discurso ha desaparecido (Ricoeur, 1995: 20) ${ }^{20}$. En esta misma línea Amado Alonso, en el clásico prefacio a la edición española del Curso de Saussure va mucho más lejos, advirtiendo que «así como la autonomía del sistema permite al autor en la sincronía descartar del funcionamiento de la lengua el elemento motor (el espíritu individual, relegado al habla), así en la diacronía los cambios resultan involuntarios e inconscientes, incapaz el hablante de intervenir en el sistema para alterarlo; y en consecuencia, la evolución del sistema es igualmente autónoma, ajena en sí misma a la historia de la civilización del pueblo que los usa. He aquí, pues, cómo, tanto del funcionamiento como de la evolución de la lengua, se consigue descartar la acción del espíritu» (Alonso, 1983: 23).

Esta apreciación de Amado Alonso resulta acertada, y se completa cuando indica que la linguíística estructural llega a una sorprendente claridad y simplicidad, pero a fuerza de eliminaciones; más aún, a costa de descartar lo esencial en el lenguaje como fenómeno específicamente humano - y por lo tanto social-, que es su capacidad de intervenir en el mundo de los hechos (Alonso, 1983: 8). El esfuerzo saussureano vacía de significado los elementos creativos y generativos en lo social del lenguaje con la finalidad de captar sus relaciones y la teoría que las explica: así, es el propio investigador el que delimita la realidad y el que decide qué niveles de ella pasan a formar parte de la teorización y cuáles son rechazados al resultar problemáticos o disfuncionales. A la hora de afrontar el problema lingüístico es necesario, por tanto, abrir el punto de vista al sujeto comunicativo, como sujeto práctico, activo y social; algo que el propio Bajtin hizo siempre con maestría: «La verdad no nace si se encuentra en la cabeza de un solo hombre, sino que se origina entre los hombres que la buscan conjuntamente, en el proceso de su comunicación dialógica» (Bajtin, 1988: 156) ${ }^{21}$.

${ }^{20}$ Se recomienda también leer la crítica que Ricoeur realiza a la narratología estructural en su obra Tiempo y narración II (Ricoeur, 1987).

${ }^{21}$ La posibilidades de desarrollo de las aportaciones de Mijail Bajtin para un encuentro entre los análisis literarios, formales y sociales del discurso en un paradigma dialogico de amplio uso en todas las ciencias humanas pueden explorarse en Pozuelo Yvancos (2004), Peytard (1995) o Holquist (1990), así como el conjunto de trabajos compilados por Vauthier y Cátedra (2003).

EMPIRIA. Revista de Metodología de Ciencias Sociales. N.ำ 12, julio-diciembre, 2006, pp. 11-35. 
Por todo esto se puede concluir que la metodología estructuralista de análisis del discurso se puede adaptar bien a géneros literarios caracterizados por cierta uniformidad básica (por ejemplo, literatura managerial, novelas policíacas, cuentos populares, libros de autoayuda, secciones periodísticas concretas como la del horóscopo, etc.). Ello se debe a que estos géneros pueden reducirse a algo aproximado a un puro argumento (Stubbs, 1987: 196). Por eso, el análisis estructural, pese a sus limitaciones, es pertinente de ser aplicado en una sociología de los textos que, como señala acertadamente van Dijk, tendrá «...la tarea específica de mostrar cómo se manifiestan las relaciones de poder, jerarquía y fuer$\mathrm{za}$, funciones, papeles, niveles y clases en las posibles estructuras de textos de los individuos, grupos e instituciones afectados» (van Dijk, 1992: 23). Pero el análisis del discurso no puede limitarse a las características del texto en cuanto a su estructura o forma; también debe tener en cuenta su contenido simbólico y las condiciones en que se genera su producción. La utilización de elementos semiológicos es imprescindible por cuanto permite el desciframiento de signos sociales, pero no puede limitarse a ello: debe comprender el discurso que atravie$s a$ dichos textos, dado que es un discurso social. Por tanto, no se puede perder de vista la relación del discurso con la sociedad y las relaciones de poder existentes en ella. En la investigación social, el discurso desborda al texto (Alonso, 1998: 208).

\section{CONCLUSIÓN}

Respecto a la importancia del sujeto en el análisis del discurso de filiación estructural, el debate sigue abierto: el papel que adopta el individuo y los grupos concretos en las relaciones a través de la lengua sigue siendo problemático. A lo largo de toda su obra Barthes concede una escasa importancia al agente, que se encuentra sometido por completo al sistema. Además, en el cuerpo teórico de Barthes del que se puede derivar una metodología del análisis del discurso - pues del que se vuelca hacia el postestructuralismo más pansensualista e informal ya no es necesario ni planteárselo-, asistimos a una peligrosa reducción del pensamiento a la lengua, lo cual no es sino una potente y abierta maniobra cientifista para eliminar lo relativo al actor, cuyos comportamientos impredecibles podrían desbaratar la perfección del sistema lógico creado por el investigador. Se consigue, pues, la desocialización implícita de la comunicación humana, reduciendo la lengua a un sistema lógico o formal de carácter inmanente, que termina por asimilar al hombre y al mundo socialmente significado al esquema implícito del lenguaje. No obstante, aunque sea cierto que el hombre es a través del lenguaje como recuerda y reconoce el mundo, el mundo -y más el mundo social - no es sólo lenguaje (Alonso 2005. 265-272).

En este punto llegamos al tema concreto de las dificultades de la metodología estructural y la teoría linguística en lo que se refiere al intento de abordar con ellas el análisis de lo social. Es verdad, como se ha señalado antes, que gracias a 
la apertura semántica de las Mitologías, hay un acceso a lo social: Pero Barthes ha supuesto también una especial aceleración y expansión de ese traspaso de la metodología linguística a todos los ámbitos sociales, dando paso a la agudización de la pretensión de ciertas escuelas y autores de realizar no tanto una análisis de los discursos situado y contextualizado en marcos sociales, sino de decretar una especie de «todo es lenguaje» o, si se quiere, de convertir la sociología en un residuo secundario y banal de una omnipotente y universal metodología lingüística, que no sólo la presupondría, sino que la comprendería y asumiría. Los enfoques que se inspiran más o menos directamente en la semiología general, ya sea en la versión directa de Barthes (1990), ya sea en la de cualquiera de sus muchos seguidores, se encuentran tarde o temprano con el problema de analizar el lenguaje como un hecho material y social; y en este sentido, a partir de una referencia notablemente idealista como es la lingüística saussuriana, es difícil analizar los actos de habla como actos pragmáticos, realizados por actores en situación, contexto y marco histórico, y con pretensiones de sentido social.

La producción y comunicación del sentido se realiza, en el análisis estructural. a través de la diversificación y la multiplicación de categorías opuestas o códigos binarios - puro e impuro, limpio y sucio, comestible y no comestible, orden y desorden, masculino y femenino, dulce y amargo, antiguo y moderno, crudo y cocido, etc.- lo que permite clasificar los elementos simples de la enunciación según su identidad en un sistema de signos; y aquí no hay ninguna duda de que estos enfoques estructuralistas y semiológicos son extremamente fecundos, y permiten ordenar de manera satisfactoria una masa de datos. Sin embargo, nos dejan absolutamente sin respuesta ante procesos culturales donde domina lo cognitivo - tal es la línea de explicación propuesta por Mary Douglas (1999: 117-134)—, donde los estilos de comunicar se derivan de los estilos de pensar, y los actos de habla se encuentran más cerca de la convicción que de la simple imposición del sentido; o donde los actores, antes de ser sujetos sujetados por la lengua son agentes para los que el momento de producción de la acción comunicativa es también un momento de reproducción, pero siempre mediado por los contextos de desempeño cotidianos de la vida social - como se ha repetido insistentemente desde la teoría de la estructuración (Giddens 1995)—; o, finalmente, como Pierre Bourdieu ha argumentado, donde son las razones prácticas de los sujetos concretos que usan la lengua -con todas sus limitaciones estructurales, pero también con todas sus potencialidades - las que conforman los actos de habla con sentido, en un campo que siempre es un espacio de poderes (Bourdieu 1997).

El análisis estructural y la semiología de Barthes no constituyen un análisis de las razones prácticas del enunciar, puesto que en ellos todo sentido es derivado de la disposición estructural, dejando de lado la materialidad social del lenguaje y de los marcos que hacen comprensibles los discursos. En una palabra, el enfoque semiológico cuando aborda el discurso como práctica es reduccionista, en cuanto que no se interesa tanto por lo social, en su relación con la construcción del sujeto que comunica en una situación de conflicto de intereses en el ám- 
bito de la significación, como por la geometría formal de una enunciación formal que desprende su sentido del encaje de elementos mínimos de estructuración significante. Un análisis como el que Barthes practica se inscribe, implícitamente, en el marco del paradigma mentalista; así bordea, de forma permanente, el peligro de caer en el repetido idealismo que ha impregnado el análisis contemporáneo de inspiración estructuralista, que cree que analizar o interpretar un texto en lo social es realizar una lectura o decodificación interna de signos que el investigador compone como un puzzle, sin necesidad de introducir el poder social de los actores en juego, incluido el poder del investigador. $Y$ es que «leer no es sólo un proceso psicobiologico realizado con unidades linguísticas y capacidades mentales. También es una práctica cultural insertada en una comunidad particular, que posee una historia, una tradición, unos hábitos y unas prácticas comunicativas especiales» (Cassany, 2006: 28). En el modelo de Barthes, la interpretación social de los discursos se hace como si fuera una lectura de un sentido oculto de los mensajes, la cual se deriva de un conjunto de articulaciones estructurales que está implícita en sus reglas de composición. No se hace, por tanto, como el seguimiento de los conflictos de sentido en el campo de comunicación de sujetos sociales reales con razones para realzar sus prácticas discursivas. $\mathrm{El}$ análisis propiamente sociológico de los discursos sólo puede realizarse dando cuenta de la capacidad de estructurar y diversificar los instrumentos de comunicación - como acción - que tienen los actores sociales, reproduciendo, pero también construyendo y reconstruyendo sus condiciones de enunciación de los discursos. Por tanto, la metodología de análisis del discurso inspirada en el estructuralismo de Barthes puede tener sentido para el sociólogo, pero debe ser completada con un acceso a las esferas semántica y pragmática del discurso, esto es, a los actores y a los contextos concretos: a lo social, en definitiva.

\section{BIBLIOGRFÍA}

Alonso, Amado (1983): «Prólogo a la edición española», en Saussure, Ferdinand de, Curso de lingüística general, Losada, Buenos Aires.

ALONSO, Luis Enrique (1998): La mirada cualitativa en sociología, Fundamentos, Madrid.

- (2005), La era del consumo, Siglo XXI, Madrid.

BaJtin, Mijail (1988): Problemas de la poética de Dostoievski, Fondo de Cultura Económica, México.

- (1991): Teoría y estética de la novela, Taurus, Madrid.

BARDIN, Laurence (1986): Análisis de contenido, Akal, Madrid.

BARTHES, Roland (1972): Crítica y verdad, Siglo XXI, Buenos Aires.

- (1973): El grado cero de la escritura seguido de Nuevos ensayos críticos, Siglo XXI, Buenos Aires.

- (1974): «Introducción al análisis estructural de relatos», en Barthes, Roland et al, Análisis estructural del relato, Tiempo Contemporáneo, Buenos Aires.

- (1978): Roland Barthes por Roland Barthes, Kairós, Barcelona.

EMPIRIA. Revista de Metodología de Ciencias Sociales. N. ${ }^{\circ}$ 12, julio-diciembre, 2006, pp. 11-35. 
- (1980): S/Z, Siglo XXI, Madrid.

- (1982): La cámara lúcida. Nota sobre la fotografía, Gustavo Gili, Barcelona.

- (1983): Ensayos críticos, Seix Barral, Barcelona.

- (1987): El susurro del lenguaje: más allá de la palabra y la escritura, Paidós, Barcelona.

- (1990): La aventura semiológica, Paidós, Barcelona.

- (2000): Mitologías, Siglo XXI, Madrid.

- (2003): El sistema de la moda y otros escritos, Paidós, Barcelona.

Beltrán Villalva, Miguel (1991a): La realidad social, Tecnos, Madrid.

- (1991b): Sociedad y lenguaje. Una lectura sociológica de Saussure y Chomsky, Fundación Banco Exterior, Madrid.

BIERWISCH, Manfred (1971): El estructuralismo: historia, problemas, métodos, Tusquets, Barcelona.

BORGES, Jorge Luis (1990): El hacedor, Madrid, Alianza/Emecé.

Bolfvar Botía, Antonio (2001): El estructuralismo: de Lévi-Strauss a Derrida, Ediciones Pedagógicas, Madrid.

BOURDIEU, Pierre (1985): ¿Qué significa hablar? Economía de los intercambios lingüísticos, Akal, Madrid.

- (1997), Razones prácticas. Sobre la teoría de la acción, Anagrama, Barcelona.

Brown, Gillian, y Yule, George (1993): Análisis del discurso, Visor, Madrid.

CALVET, Louis-Jean (1992): Roland barthes. Una biografia, Gedisa, Barcelona.

CASSANY, Daniel (2006): Tras las líneas. Sobre la lectura contemporánea, Anagrama, Barcelona.

Clemente, Miguel y Santalla, Zuleyma (1991): El documento persuasivo. Análisis de contenido y publicidad, Deusto, Bilbao.

CoBast, Éric (2002): Mythologies de R. Barthes. Premières leçons, Presses Universitaires de France, París.

COMPAGNON, Antoine (2005): Les antimodernes: de Joseph de Maistre a Roland Barthes, Gallimard, París.

CUlleR, Jonathan (1987): Barthes, Fondo de Cultura Económica, México.

DEBORD, Guy (2000): La sociedad del espectáculo, Pre-Textos, Valencia.

DiJk, Teun A. van (1992): La ciencia del texto, Paidós, Barcelona.

- (1997): Racismo y análisis crítico de los medios, Paidós, Barcelona.

- (2003): Ideología y discurso, Ariel, Barcelona.

Douglas, Mary (1999): Estilos de pensar, Gedisa, Barcelona.

Dosse, François (2004): Historia del estructuralismo, Akal, Madrid, 2 vols.

Eco, Umberto (1985): Apocalípticos e integrados, Lumen, Barcelona.

- (1988), Tratado de semiótica general, Lumen, Barcelona.

ELIADE, Mircea (1967): Lo sagrado y lo profano, Guadarrama, Madrid.

ELIAS, Norbert (1995): Sociología fundamental, Gedisa, Barcelona.

ÉvrARD, Franck y Tenet, Éric (1994): Roland Barthes, Bertrand Lacoste, París.

FAIRCLOUGH, Norman (1990): Language and power, Longman, Singapur.

GIDDENS, Anthony (1995): La constitución de la sociedad. Bases para una teoría de la estructuración, Amorrortu, Buenos Aires

Greimas, Algirdas J. (1973): Semántica estructural, Gredos, Madrid.

HOLQUIST, Michael (1990): Dialogism. Bakhtin and his World, Routledge, Londres.

IBÁÑEz LANGLoIs, José Miguel (1983): Sobre el estructuralismo, Universidad Católica de Chile, Santiago de Chile. 
JÄGER, Siegfried (2003): «Discurso y conocimiento: aspectos téricos y metodológicos de la crítica del discurso y del análisis de dispositivos», en Wodak, Ruth, y Meyer, Michael, Métodos de análisis crítico del discurso, Gedisa, Barcelona.

Kristeva, Julia (1978): Semiótica 1, Fundamentos, Madrid.

LefeBVRE, Henri (1975): L'idéologie structuraliste, Seuil/Points, París.

LÉVI-STRAUSS, Claude (1968): Antropología estructural, Ed. Universitaria de Buenos Aires, Buenos Aires.

- (1980): Antropología estructural II, Siglo XXI, México.

- (1982): Mitológicas: lo crudo y lo cocido, Fondo de Cultura Económica, México.

- (1987): Mito y significado, Alianza, Madrid.

- (2002): El pensamiento salvaje, Fondo de Cultura Económica, Madrid.

MARANDA, Pierre (1999): "Los mitos: teología y física teórica», en Dijk, Teun A. van (ed.), Discurso y literatura. Nuevos planteamientos sobre el análisis de los géneros literarios, Visor, Madrid.

MARRo, Mabel (1999): «Roland Barthes: el lenguaje de los discursos, la ciencia de los signos, la práctica del texto», en Zecchetto, Victorino (coord.), Seis semiólogos en busca del lector, Ediciones CICCUS/La Crujía, Buenos Aires.

Millet, Louis y VARIN D'AinVelle, Madeleine (1975): El estructuralismo como método, Edicusa, Madrid.

MiLnER, Jean Claude (2004): El paso filosófico de Roland Barthes, Amorrortu, Buenos Aires.

MounIN, Georges (1972): Introducción a la semiología, Anagrama, Barcelona.

PAvel, Thomas G. (1999): «Narraciones literarias», en Dijk, Teun A. van, Discurso y literatura. Nuevos planteamientos sobre el análisis de los géneros literarios, Visor, Madrid.

PEYTARD, Jean (1995): Mikhail Bakhtine. Dialogisme et analyse du discours, París, Bertrand Lacoste.

PiZARRo, Narciso (1979): Metodología sociológica y teoría lingüística, Alberto Corazón, Madrid.

Pozuelo Yvancos, José María (1994): «La teoría literaria en el siglo XX», en Villanueva, Darío (ed.), Curso de teoría de la literatura, Madrid, Taurus.

- (2004): Ventanas de la ficción. Narrativa hispánica siglos XX y XXI, Península, Barcelona.

PROPP, Vladimir (1981): Morfología del cuento, Fundamentos, Madrid.

RicoEUR, Paul (1969): Finitud y culpabilidad, Taurus, Madrid.

- (1973): El conflicto de las interpretaciones. II. Hermenéutica y estructuralismo, Ediciones Megápolis/La Aurora, Buenos Aires.

- (1987): Tiempo y narración II: configuración del tiempo en el relato de ficción, Ediciones Cristiandad, Madrid.

- (1995): Teoría de la interpretación. Discurso y excedente de sentido, Siglo XXI, México D. F.

SonTAG, Susan (1983): «La escritura misma: sobre Roland Barthes», epílogo a Barthes (1983).

STUBвS, Michael (1987): Análisis del discurso. Análisis sociolingüistico del lenguaje natural, Alianza, Madrid.

ToDOROV, Tzvetan (1974): «Las categorías del relato literario», en Barthes, Roland et al, Análisis estructural del relato, Tiempo Contemporáneo, Buenos Aires.

TrifonAS, Peter. P. (2004): Barthes y el imperio de los signos, Gedisa, Barcelona. 
VARGAS LlOSA, Mario (2002): El lenguaje de la pasión, Punto de Lectura, Madrid.

VÁZQUEZ, Ignacio y ALDEA, Santiago (1991): Estrategia y manipulación del lenguaje: análisis pragmático del discurso publipropagandístico, Universidad de Zaragoza, Zaragoza.

VAUTHIER, Bénédict y Cátedra, Pedro M. (eds.) (2003): Mijail Bajtin en la encrucijada de la hermenéutica y las ciencias humanas, SEMYR, Salamanca.

Voloshinov, Valentin N. (1992): El marxismo y la filosofía del lenguaje, Alianza, Madrid.

WODAK, Ruth, y MEYER, Michael (2003): Métodos de análisis crítico del discurso, Gedisa, Barcelona. 


\section{RESUMEN}

Este artículo pretende hacer una reflexión sobre la posibilidad de un análisis del discurso sociológico basado en los estudios semiológicos del pensador estructuralista francés Roland Barthes. Se plantearán así en profundidad las principales líneas teóricas de su famoso análisis estructural del relato, así como la apertura de la semiología a lo social en su trabajo en Mitologías. Finalmente, se esbozará una crítica metodológica a las limitaciones de este análisis estructuralista, desde una perspectiva en la que se dé prioridad al estudio de los actores sociales y a los contextos concretos.

\section{PALABRAS ClAVE}

Análisis del discurso, texto, Roland Barthes, estructuralismo, semiología, mitología.

\section{ABSTRACT}

This paper tries to reflect upon the possibility of a sociological discourse analysis based on the semiological works of the French structuralist thinker Roland Barthes. Thus the main theoretical lines of his famous Structural Analysis of the Tale will be highlighted, as well as his semiological opening to the social in his work Mythologies. Finally, a critical methodology on the limitations of this structural analysis will be outlined from a perspective in which both social actors and concrete contexts may be priorised in th analysis.

\section{KEYWORDS}

Discourse analysis, text, Roland Barthes, structuralism, semiology, mythology. 